\title{
THE EXPERIENCES OF COMMENCING AN IN SITU SIMULATION EDUCATION PROGRAMME IN AN ACUTE AND CRITICAL INPATIENT HOSPITAL ENVIRONMENT
}

\author{
Joanne Robertson-Smith and John Edmond
}

\section{INTRODUCTION}

Simulation-based experiences (SBE) are being utilised increasingly within healthcare environments worldwide (Motolo, Devine, Chung, Sullivan, \& Issenberg, 2013). SBE may improve a learner's technical and non technical skills (Abe, Kawahara, Yamashina, \& Tsuboi., 2013) which includes their knowledge, confidence, teamwork, communication, and the understanding of healthcare professionals' roles. Improved team work, interprofessional collaboration, communication, and co-ordination that can lead to an increase in the quality of patient care and ultimately improved patient outcomes (Weller \& Civil, 2017; Decker, et. al., 2015). In situ SBE refers to an educational opportunity which occurs within a patient care setting where healthcare professionals would normally provide their services (INACSL Standards Committee, 2016a), allowing teams to test their own effectiveness as well as hospital processes (Spur, Gatward, Joshi, \& Carly, 2016).

This paper will reflect on the experiences of the first two years of an in situ SBE programme which commenced in October 2017. The in situ SBE described predominantly occurred within a coronary care unit, on cardio-thoracic, respiratory, cardiology and renal wards as well as a cardiac catheter lab. The authors also extended their in situ SBE into other specialist areas within the tertiary hospital they work in. The content will reflect on the impact upon clinical practice, latent safety risk identification, the challenges experienced and interprofessional as well as interdepartmental SBE.

\section{METHOD}

\section{About the environment}

Dunedin Public Hospital (DPH) is situated in the lower South Island of New Zealand. The hospital is a 388-bed tertiary facility employing over 3,000 staff and servicing the Otago and Southland population of around 300,000. The cardiology department is the regional centre for myocardial infarction management, as well as being a cardiac surgical centre.

\section{The in situ SBE programme}

The Otago Simulation Interest Group (OSIG) was formed in 2017 to provide an organisation wide SBE network, to assist in establishing and maintaining SBE within differing clinical areas. OSIG established standards and encouraged the sharing of resources and ideas between those undertaking SBE within the Otago and Southland areas. With the advice and encouragement of OSIG we commenced an in situ SBE programme in the cardiology/respiratory/ renal wards. 
The framework of SBE usually consists of; pre-planned, measurable objectives; a comprehensive pre-brief; the simulation scenario; and a reflective and structured debrief to conclude the learning experience (INACSL Standard Committee, 2016b). Using this structure, the in situ SBE sessions were devised and run.

Within our clinical environments, over 30 in situ SBEs were undertaken during the first two years (Table I). These in situ SBE usually took place over the 30 minute period of handover time between the morning and afternoon shifts for nuses. The timing was to allow for maximum participant attendance and allowing an increased chance to undertake SBE repeatedly. The scenarios utilised included; caridiac arrest (ventricular fibrillation (VF), ventricular tachycardia (VT) and pulseless electrical activity; anaphylaxis; hypoglycaemia; airway management; opiod induced ventilatory impairment (OIVI); and a deteriorating patient scenario. The majority of in situ SBE were VF or VT cardiac arrest scenarios. The educational objectives of the cardiac arrest SBE were to provide exposure to the New Zealand Resuscitation Councils (NZRC) algorithm for Advanced Cardiac Life Support (ACLS) (New Zealand Resuscitation Council, 2016), resuscitation drugs, and resuscitation equipment. Staff were asked to simulate how they would respond to an inpatient who went into a cardiac arrest. Equipment included a low fidelity mannequin, real drugs, real documentation, and a device which allowed an altered heart rhythm to be displayed on the M4735A HeartStart XL Defibrillator/Monitor (Phillips Healthcare, Andover, MA) or Phillips HeartStart FR2 Defibrillator (Phillips Healthcare, Eindhoven, The Netherlands).

\begin{tabular}{|c|c|c|}
\hline Date & Type of SBE and location & Attendants \\
\hline $20 / 10 / 17$ & VF arrest & Nursing (10) Student Nurses (2); Facilitator (I) \\
\hline $30 / 10 / 17$ & VF arrest & Nursing (9) Student Nurses (2) Facilitators (3) \\
\hline $07 / 12 / 17$ & VF arrest & Nursing (8) Facilitators (3) \\
\hline $14 / 12 / 17$ & VF arrest & Nursing (8) Facilitators (3) \\
\hline $01 / 02 / 18$ & VF arrest & Nursing (5) Medical (3) Facilitators (2) \\
\hline $15 / 02 / 18$ & *VF arrest & Nursing (6) Facilitator (I) \\
\hline $15 / 02 / 18$ & VF arrest & Cancelled due to patient acuity \\
\hline $15 / 03 / 18$ & VF arrest & $\begin{array}{l}\text { Nursing (7) Facilitators ( } 2 \text { ) - moved to } 7 \text { th floor seminar } \\
\text { room due to patent acuity. (Medical Ward Clinical Nurse } \\
\text { Educator present to learn) }\end{array}$ \\
\hline $29 / 03 / 18$ & Hypoglycaemia & Cancelled due to staff sickness \\
\hline 05/04/18 & Hypoglycaemia & Nursing (13) Facilitators (3) \\
\hline $23 / 04 / 18$ & VF arrest & $\begin{array}{l}\text { One SBE after the other with senior nurses from throughout } \\
\text { the hospital }\end{array}$ \\
\hline $30 / 04 / 18$ & VF arrest & Cancelled re: acuity \\
\hline 09/05/18 & VF arrest & Medical (6) Nursing (I8) Student Nurse (I) Faculty (2) \\
\hline $15 / 05 / 18$ & VF arrest & $\begin{array}{l}\text { One SBE after the other with senior nurses from throughout } \\
\text { the hospital. }\end{array}$ \\
\hline $23 / 05 / 18$ & VF arrest & Nursing (16) (7 from the medical ward). Facilitators (3) \\
\hline $31 / 05 / 18$ & VF arrest & Cancelled due to staff sickness \\
\hline $18 / 06 / 18$ & * VF arrest - Surgical floor & Nursing (I3) Student nurse (I) Facilitators (2) \\
\hline $20 / 06 / 18$ & VF arrest & Medical (5) Nursing (17) Facilitators (3) \\
\hline $30 / 10 / 18$ & VF arrest & $\begin{array}{l}\text { Medical (9) Nursing (14) Allied (2) Student Nurses (4) } \\
\text { Student Allied (I) }\end{array}$ \\
\hline
\end{tabular}




\begin{tabular}{|c|c|c|}
\hline $12 / 1 \mid / 18$ & $\begin{array}{l}\text { *Anaphyaxis Radiology } \\
\text { Department }\end{array}$ & $\begin{array}{l}\text { Medical (4) Nursing (3) Medical Imaging Technologist (MIT) } \\
\text { (7) Faculty (3) }\end{array}$ \\
\hline $16 / 01 / 19$ & *Anaphylaxis - Oncology Day Unit & Nursing (12 - 4 participants 8 observers) - Faculty (2) \\
\hline $29 / 01 / 19$ & PEA Arrest & Nurses (7) \\
\hline $23 / 02 / 19$ & Anaphylaxis & Nursing (9) Medical (3) \\
\hline $28 / 02 / 19$ & Anaphylaxis & Nurses (8) \\
\hline $26 / 03 / 19$ & VF arrest & Medical (2) Nursing (8) Student Nurse (I) \\
\hline 02/04/19 & VT arrest (Cath Lab) & Nursing (5) Allied (4) Student Allied (2) Faciltators (2) \\
\hline $04 / 04 / 19$ & VT arrest (Cath Lab) & $\begin{array}{l}\text { Nursing (3) MIT (3) Physiologist (5) Trainee Physiologist (I) } \\
\text { Facilitators (3) }\end{array}$ \\
\hline 04/04/19 & VT arrest (Cath Lab) & Cancelled - Facilitators (3) \\
\hline 04/04/19 & VF arrest with airway management & Nursing (18) \\
\hline $20 / 06 / 19$ & Airway management & Nursing (9) Physiotherapists (3) Facilitators (2) \\
\hline $31 / 07 / 19$ & VT arrest (Cath Lab) & Cancelled - Facilitators (3) \\
\hline $31 / 07 / 19$ & VF arrest & Medical (2) Nursing (9) Student Nurse (I) \\
\hline I5/08/19 & VF arrest & Nursing (9) Student Nurse (I) Physiotherapist (I) \\
\hline $29 / 08 / 19$ & $\begin{array}{l}\text { Deterriorating Patient - } \\
\text { Interdepartmental Cardiology / } \\
\text { renal ward and ICU }\end{array}$ & $\begin{array}{l}\text { Medical (5 - } 3 \text { Ward; } 2 \text { ICU) Nurses }(7-5 \text { Ward; } 2 \text { ICU) } \\
\text { Charge Nurse (I) Clinical Team Co-ordinator (I) }\end{array}$ \\
\hline 19/09/19 & $\begin{array}{l}\text { Opioid Induced Ventilatory } \\
\text { Impairment }\end{array}$ & Nursing (I2) Charge Nurse (I) Physiotherapist (I) \\
\hline $24 / 10 / 19$ & VF arrest & $\begin{array}{l}\text { Nurses (I) Charge Nurse (I) Physiotherapists (I0) } \\
\text { Occupational Therapist (I) Facilitators (2) }\end{array}$ \\
\hline $30 / 10 / 19$ & VF arrest & $\begin{array}{l}\text { Medical (3) Nursing (II) Physiotherapist (2) Pharmacist (I) } \\
\text { Social Worker (I) }\end{array}$ \\
\hline
\end{tabular}

Table I. Summary of simulation-based educations undertaken until from October 2017 to October 2019.

*Other areas outside of the 7th floor DPH

In the early days of facilitating in situ SBE the cardiac arrest scenarios generally continued until the SBE mannikin simulated a return to a normal sinus rhythm, to make the participants feel a sense of success. Once the participants were more confident with the programme, and the whole process of the SBE, we changed some outcomes to be negative for the patient (if this was clinically appropriate) depending on the scenario and the learning points envisaged.

The facilitators involved in the SBE programme on the 7th floor of Dunedin Public Hospital (DPH) during this time included a Clinical Nurse Educators (CNE); a Cardiologist, an Associate Charge Nurse Manager (ACNM) who covered the respiratory/cardiothoracic ward and the coronary care unit, and an Enrolled Nurse (EN). The Cardiologist was a NZRC Core Advanced Rescuer Course instructor, the CNE, and ACNM had completed the NZRC CORE Advanced Rescuer Course.The CNE, Cardiologist and EN had participated in formal education on simulation delivery. 


\section{Impact on practice}

\begin{tabular}{|c|c|c|}
\hline Latent risk category & Examples of risk & Corrective action \\
\hline Equipment & $\begin{array}{l}\text { - AED set to wrong program (three } \\
\text { stacked shocks) } \\
\text { - PEEP valve fell apart } \\
\text { - Defibrillator placed on bed for transport, } \\
\text { easy to knock off }\end{array}$ & $\begin{array}{l}\text { - Incident report and updated program } \\
\text { immediately } \\
\text { - Incident report and ordered new style of } \\
\text { PEEP valve } \\
\text { - Tray recommended and able to be } \\
\text { sourced from central area. }\end{array}$ \\
\hline $\begin{array}{l}\text { Environment/staffing } \\
\text { Knowledge and skills } \\
\text { Recurring risks }\end{array}$ & $\begin{array}{l}\text { - Delayed chest compressions or } \\
\text { application of defibrillation pads } \\
\text { - Unaware where anaphylaxis box is stored } \\
\text { - Bag-valve mask left on bed with } \\
\text { defibrillation } \\
\text { - Medication not checked } \\
\text { - Unfamiliar with NZRC ACLS flow } \\
\text { diagram or not used } \\
\text { - Not transferring NZRC CORE training } \\
\text { into clinical the environment } \\
\text { - Uncertainty of roles } \\
\text { - Unfamiliarity with emergency drugs } \\
\text { - Closed loop communication absent and/ } \\
\text { or participants quietly spoken. } \\
\text { - Team Leader/Leadership not apparent } \\
\text { (not transferring NZRC CORE Advanced } \\
\text { Rescuer training into clinical environment) } \\
\text { - Unfamiliar with resuscitation } \\
\text { documentation }\end{array}$ & $\begin{array}{l}\text { - SBE reports circulated and education } \\
\text { added to yearly CPR updates for nurses } \\
\text { - Staff to re-familiarise (already in nursing } \\
\text { orientation checklist) } \\
\text { - Reminder to remove } \\
\text { - Reminder during debrief to check } \\
\text { - } \text { - Educatications } \\
\text { meetings and familiarisation via team } \\
\text { - Yearly updates became in situ SBE } \\
\text { involvement } \\
\text { - Education and discussions occurred } \\
\text { - Education undertaken immediately with } \\
\text { teaching tray } \\
\text { - Discussed in debrief } \\
\text { - Asked NZRC CORE Advanced Rescuers } \\
\text { to role model resuscitation leadership } \\
\text { role } \\
\text { - Education given as able and advice to } \\
\text { familiarise self in own time }\end{array}$ \\
\hline
\end{tabular}

Table 2. Latent safety risks discovered as well as solutions utilised during in situ SBE programme.

\section{Knowledge deficits revealed}

Our in situ SBE program showed that participants of differing professions, as well as experience levels, asked questions and requested clarification of our clinical quidelines. These factual knowledge questions included how and when to give resuscitation medications (adrenaline and amiodarone).

A further knowledge deficit noted was following a change in the way pharmacy stored the drugs within the emergency trolley. The SBEs regularly had some participants who were not aware of the contents of the emergency trolley's drug tray. This knowledge deficit was considered potentially related to a paper map cover being placed over the drug tray by pharmacy. The map indicated where the drugs were within the trolley. The sealed and dated tray meant that daily checks of indivdual drugs within the emergency trolley were no longer required, which saved time. However, this change has limited the staff exposure and familiarity to the emergency drugs. To resolve the lack of familarity with ermergency drugs, as well as the SBEs, mini education sessions occurred, utilising a teaching tray holding the real drugs during the clinical huddles, or as the opportunity arose. 

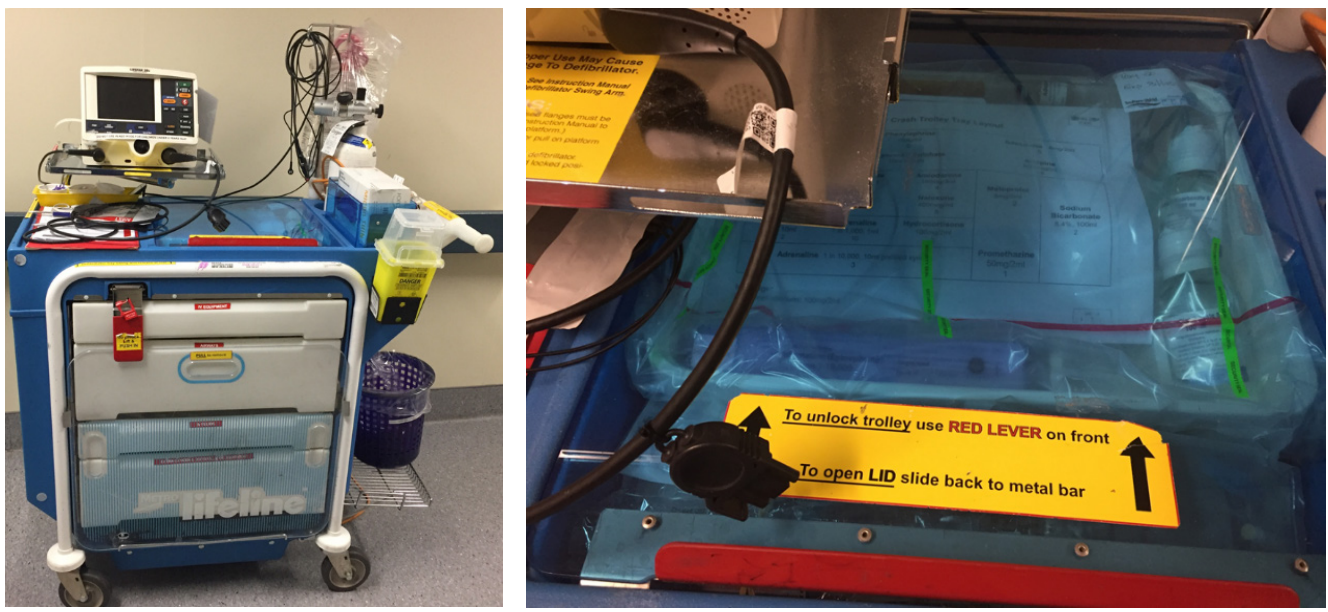

Figures | \& 2. Drug tray utilised for teaching purpose. A significant knowledge deficit was revealed and responded to. Source: Joanne Robertson-Smith.

Significant knowledge deficits were revealed and resolved and knowledge transfer was reportedly occurring into actual patient care. The most significant feedback came from a member of the clinical leadership team who acknowledged the positive impact of in situ SBE translating into improved teamwork and understanding of roles during a cardiac arrest. This was revealed specifically during a cardiac arrest which occurred in the ward. The caridac arrest could have been quite traumatic, but two members of the team reported feeling more positive than they expected due to the previous practice they had undertaken during SBE. Additionally, feedback was received from nursing leadership that teams appeared more confident with cardiac arrest scenarios in general.

From the CNE's perspective the initial learner responses to in situ SBEs appeared very positive and many staff reported that they intented to participate repeatedly as participating in the in situ SBE made them feel more confident, they valued it and saw benefit. These benefits included improved communication, teamwork, and an enhanced understanding of roles, including those of other healthcare professions. There was an acknowledgement from staff that it was valuable to practise clinical situations which do not happen very often, but when they do require a prompt and confident response. The feedback was simlar to a Canadian paediatric acute inpatient study which discussed participants who valued interprofessional SBE, wanted more, and shared that SBE increased participant confidence, communication and their understanding of healthcare professionals roles (Kotsakis, Mercer, Mohseni-Bod, Gaiteiro \& Agbeko, 2014).

During the second year of our in situ SBE program new defibrillators were introduced to our hospital. In situ SBE was utilised to assit with embedding the new device into clinical practice. Some participants reported that it was great to practise utililsing the equipment (especially new devices like the defibrillator) and visualise and discuss the emergency drugs. Some participant reports stated that this familiarisation assisted with decreasing staff anxiety about patient resuscitation as well as highlighting aspects around performance which could be improved.

\section{Value for new staff}

SBE has noted to be value for our new staff members, specifically one new Registered Nurse (RN) who was involved in an in situ SBE described here. One of the advantages in situ offers is the ability to easily follow up with 
staff after the SBE as the facilitator and participants share the same environment. The RN discussed the SBE with the facilitator and felt that the understanding she had gained from the SBE was very valuable. Later on that day the new RN was involved in the care of a patient who had a prolonged refractory VT/VF cardiac arrest. The next day the new RN shared that she was not sure how she would have managed had she not undertaken the in situ SBE the day before. During the cardiac arrest, the new RN competently and confidently undertook the airway management role within the cardiac arrest.

\section{Latent risk identification}

There are risks related to clinical practice and it is important to decrease errors and increase patient safety (Motolo, et. al., 2013). Healthcare is complex and latent risks can change suddenly. Sharing learning points around patient safety risks are important (Spur, et. al., 2016). Possibly, if we share our identified latent safety risks, these errors can be eliminated (Ma, Bunting, Avery, Fawcett \& Carter, 2018) and sharing our findings inside and outside our organisations is subsequently of great benefit.

Our in situ SBE programme discovered a significant and surprising latent safety risk in May 2018. During an in situ SBE it was identified that the Philips Heartstart FR2 automated external defibrillators (AEDs) behaved unexpectedly. Upon investigation, the AED programme was set to an outdated programme based on the previous NZRC's ACLS algorithim. This pre-20I0 algotithim recommended clinicians administered three stacked shocks in the presence of $\mathrm{VF}$ or $\mathrm{VT}$, before users commenced chest compressions. In our simulation, there was confusion and delay in treatment as the device advised that chest compressions be delayed as the device attempted to deliver three shocks, whereas the staff expected a single shock. This was recognised as a serious patient latent safety risk and was escalated immediately to senior management and resolved. The FR2 AEDs throughout the hospital were updated very quickly.

A second important latent risk identified was that a PEEP value was also used in an in situ SBE which came apart. Several different pieces of the valve ended up in different parts of the four bedded room. After this, another

style of PEEP valve was ordered for the clinical environment, which was subsequently successfully tested in an in situ SBE.

An additional latent safety risk was noted within the Cardiac Catheter Lab (Catheter Lab) environment. The risk involved the Catheter Lab team being led by the interventional procedure operator during ACLS, which is not best practice. Nursing staff, or not primary operator medical staff, should also be comforable to lead an ACLS scenario within the Catheter Lab allowing the operator to focus on the procedure. A nursing 'team leader' role was created within the Catheter Lab, and rotated each

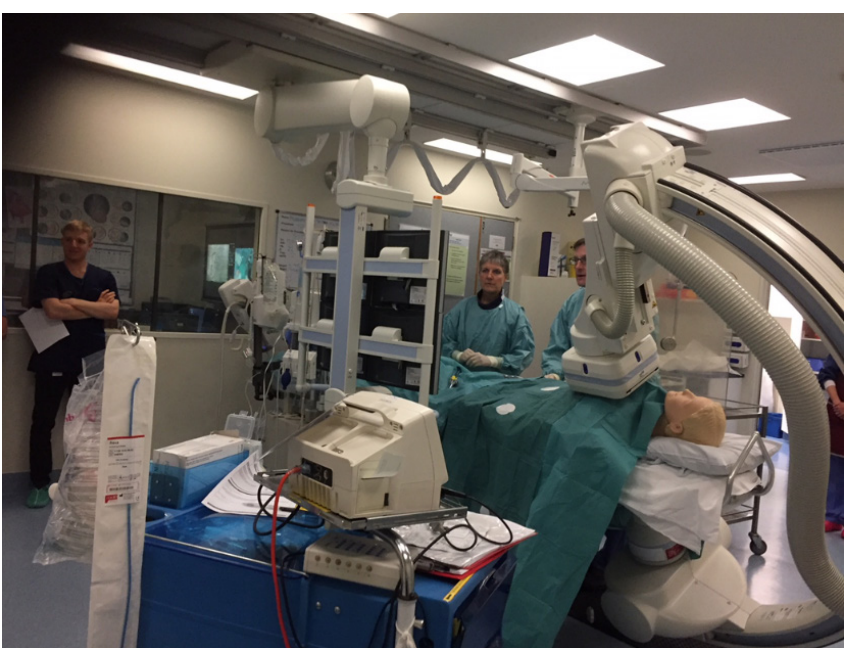

Figure 3. Catheter Lab in situ SBE which allowed staff to practice the newly created 'Team Leader' role. Source: Joanne Robertson-Smith. 
day, to prompt staff to take this lead if required. This was a role that was then able to be practised again via in situ SBE.

Latent safety risk identification is one of the many good reasons to commence an in situ SBE programme (Garden, et. al., 2010). There are many publications on latent safety risk identification with in situ SBE, including conference proceedings in which the authors stated that they introduced in situ SBE to exposed latent threats within their healthcare environments (Ma, et. al., 2018; Thomson, Tan, Hellings, \& Frys, 2016; Duffy, Brown, \& Overly, 20I2; Yajamanyam, Sohi, King, Wikey, \& Sinclair, 2012). These presentations revealed concealed patient safety issues and one department identified 20 significant risks out of 54 SBEs (Duffy et al., 2012).

Garden et al, (2010) shared their initial observations of an in situ simulation training programme in Wellington Hospital, which focused on paediatric cardiac arrest scenarios. These authors identified many latent safety errors, the most significant was the inconsistency in the ability of staff to unlock and open their resuscitation trolley. Other studies shared that within 90 SBEs undertaken they identifiyng 73 latent safety threats (Patterson, Leis, Falcome, Le Master \& Wears, 20 I3) and within II4 SBE undertaken just over one (I.I) latent safety threats were discovered per scenario they facilitated (Cauto, Bareto, Morcon, Matra \& Acors, 2018). The highest proportion (4I\%) of Cauto and colleagues discovered latent safety threats were attributed to equipment failure.

Equipment failure findings serve to remind us of the importance of authenticity in our in situ SBE programmes, so we are aware of where the potential equipment failures exist. Authenticity, or maintaining normal departmental processes is more likely to reveal latent safety errors (Spur, et. al., 2016). In undertaking an in situ SBE within our Radiology department, one facilitator brought in equipment from another area, which Radiology would not stock. A co-facilitator who observed this reminded the facilitators of the importance of keeping the SBE authentic, to test the departments own processes. The additional equipment was removed from the SBE. Authenticity meant the clinical environment having only what the staff would normally use (not what we could bring in from elsewhere), therefore removing this equipemnt meant the Radiology department's systems were authentically tested.

\section{CHALLENGES}

It is acknowledged that it can be difficult to establish a simulation programme within hospital clinical areas (Spur, et. al., 2016). Despite the positive outcomes mentioned above, there were many in situ SBE facilitation challenges. Our challenges included co-facilitator availability, a lack of realism, and some SBE participation aversion.

Colleagues (both facilitators and participants) were uncertain in their ability to participate in our planned in situ $\mathrm{SBE}$. This is a reflection of the busy clinical environments in which healthcare professionals work in.

As noted previously, authenticity is an important aspect to our simulation programme. Making SBE as real as possible, utilising real clinical areas and real equipment, is beneficial not only for revealing latent safety risks but for also making the SBE realistic enough for the participants to engagement in it effectively. A lack of realism was consistently fedback in the early days of our in situ SBE programme, but improved with increased participant exposure. This change was not due to an increase the fidelity of the SBE undertaken, therefore we feel it is most likely due to participants having repeated exposure to in situ SBE. Realism became a regular discussion point during the pre-brief, and without this discussion the lack of realism experienced by participants would often become a major distractor for participants during the debrief.

The prebrief also involves creating a safe learning environment and our in situ SBE programme believes this is important as SBE scenarios tend to challenge participants and failures can be generated and consideration to the subsequent negative emotions and how to avoid them should occcur (Rudolph, Simon, Rivard, Dufresne \& Raemer, 2007). In addition to creating a safe learning environment for the participants however, the prebrief 
also allows the development of a shared understanding with regard to the scenario and the fidelity, prior to commencing the simulation itself.

SBE participation aversion was noticed and it was disclosed by some individuals that they felt they had never been a part of in situ SBE before. Younger staff appeared more familiar and comfortable with SBE. In two of our SBE, a student nurse and newly practicing $\mathrm{RN}$ confidently took the first responder role. We considered it is likely this confidence is related to the undergraduate nursing education curriculum in which students undetake SBE. The SBE participation aversion appears to have decreased as SBE becomes more frequently utilised.

\section{Interprofessional education}

The in situ SBE programme has given the opportunity to engage in interprofessional education (IPE), which is when two or more professionals engage in a healthcare experience to achieve a shared outcome or objective. The World Health Organisation sees IPE as a key factor in obtaining complex healthcare goals now and into the future (Reeves, Perrier, Goldman, Freeth \& Zwarenstein, 2013). IPE will assist healthcare professional's skills to work in a collaborative manner and this is critical to the provision of excellent healthcare delivery, especially to complex patients.

In October 2017 our in situ SBE programme commenced utilising nurses only. By February 2018 the inclusion of the medical profession occurred. The majority of medical participants were Trainee Interns and House Officers. At the end of the two year period described, our SBE programme began co-facilitating with a physiotherapist and had physiotherapy participants and occassionally members of differing healthcare professions (see Table I).

\section{Interdepartmental education}

Our SBE programme extended to our Dialysis and Radiology departments where we facilitated SBE. We also assisted other departments by co-faciltiating and sharing what we had learnt. Resources were shared between departments and this was encouraged by OSIG, saving time planning.

One of our most rewarding and challenging SBE was an interdepartmental SBE, which was undertaken between the cardiology and renal acute care ward teams and the Intensive Care Unit. The scenario was a cardiology patient who went into a sudden pulmonary odema. This gave the acute care area the chance to practise the newly established observation early warning score and escalation pathway. There was also a newly established Clinical Team Co-ordinators (CTC) role within Dunedin Hospitial, which was a nursing leadership role to assist with patient deterioration situations. The SBE gave us an opportunity to practise and reflect upon this new role. This was the first time testing the new innitative and it was viewed very positively by most of the staff involved and the facilitators. The SBE highlighted the management of a patient who may imminently require a rapid sequence intubation and the use of high flow nasal cannula and other learning outcomes were noted. Interdepartmental SBE reveal wider organisational knowledge, understanding and risks. However, the time to create and organise the larger interdepartmental SBE, as well as facilitate them, is much higher than a SBE centralised to one area.

\section{CONCLUSION}

In our experience, in situ SBE is an educational modality which provided effective clinical learning. In situ SBE also revealed educational deficits and patient latent safety risks, which could be easily resolved, within our acute and critical care clinical environments. With perseverence and flexibility, the main hurdles of co-facilitator availability and realism can be overcome. 
Joanne Robertson-Smith (100000-0003-1014-3120) MHSc, BN, RN is a Clinical Nurse Educator for the Southern District Health Board, facilitating in situ simulation frequently. Her Master of Health Science dissertation explored the experiences of clinical educators who undertake in situ simulation-based education within the hospital clinical environments.

John Edmond (100000-0002-9852-5037) MD FRCP FRACP PGDipMedEd is a Cardiologist at the Southern District Health Board and Senior Lecturer, Dunedin School of Medicine. He is an interventional cardiologist with an interest in medical education. His special interest is the use of simulation in the quality improvement and reduction of patient risk.

Correspondence to: Joanne Robertson-Smith, Southern DHB, New Zealand.

Email: Joanne.Robertson@Southerndhb.govt.nz

\section{REFERENCES}

Abe, Y., Kawahara, C., Yamahina, A., \& Tsuboi. (2013). Repeated Scenario Simulation to Improve Competency in Critical Care: A New Approach for Nursing Education. American Journal of Critical Care, 22(I):33-40 doi.org/l0.4037/ajcc20I3229

Cauto, T., Bareto, J., Morcon, F., Matra, A., \& Acors, I. (2018). Detecting latent safety threats in an interprofessional training that combines in situ simulation with task training in an ED. Advances in Simulation, 3(23), 1-7. doi:https://doi.org//0.1/86/ s41077-018-0083-4

Decker, S., Anderson, M., Boese, T., Epps, C., McCathy, J., Motola, I., Palagrias, J., Perry, C., Puga, F., Scolaro, K. (2015). Standards of best practice: Simulation standards VIII simulation enhanced interprofessional education (Sim-IPE). Clinical Simulation in Nursing, II (6), 293-297. doi:org/10.1016/j.ecns.2015.03.010

Duffy, S., Brown, L., \& Overly, F. (2012). Development of a simulation-enhanced multidisciplinary teamwork training program in a pediatric emergency department. Annual Meeting of the Society for Academic Emergency Medicine. 19, p. SI00. Chicago: Academic Emergency Medicine.

Garden, A., Mills, S., Wilson, R., Watts, P., Griffin, J., Gannon, S., Kapoor, I. (20I0). In situ simulation training for paediatric cardiorespiratory arrest: initial observations and identification of latent errors. Anaesthesia and Intensive Care, 38, 1038 - I042.

INACSL Standards Committee. (2016a). INACSL standards of best practice: SimulationSM simulation glossary. Clinical Simulation in Nursing, 12, S39-S47.

INACSL Standards Committee. (2016b). INACSL standards of best practice: SimulationTM simulation facilitation. Clinical Simulation in Nursing, 12, S16-S20.

Kotsakis, A., Mercer, K., Mohseni-Bod, H., Gaiteiro, R., \& Agbeko, R. (2014). The development and implementation of an interprofessional simulation based pediatric acute care curriculum for ward health care providers. Journal of Interprofessional Care, 29(4), 392-394. doi:.org/10.3109/13561820.2014.984018

Ma, L., Bunting, K., Avery, E., Fawcett, J., \& Carter, A. (2018). Identifying latent threats using in situ simulation in adult ICU. Journal of the Intensive Care Society, 19(2 Supplement I), pp. 139-140.

Motolo, I., Devine, L., Chung., H., Sullivan, J., \& Issenberg, B. (2013). Simulation in healthcare education: A best practice evidence practical guide. AMEE Guide No. 82. Medical Teacher, 35, el5II-el530.

New Zealand Resuscitation Council . (2016). New Zealand Resuscitation Council Whakahauroa Aotearoa Guidelines. Retrieved May 14, 2019, from https://www.nzrc.org.nz/guidelines/

Patterson, M., Leis, G., Falcome, R., Le Master, T., \& Wears, R. (2013). In situ simulation: detection of latent safety threats and team training in a high risk emergency department. BMJ Quality and Safety, 22(6), 468-477.

Reeves, S., Perrier, L., Goldman, J., Freeth, D., \& Zwarenstein, M. (2013). Interprofessional education: effects on professional practice and healthcare outcomes (update) (Review). The Cochrane Collaboration, 3, I-49. The Cochrane Collaboration, 3, $1-49$ 
Rudolph, J., Simon, R., Rivard, P., Dufresne, R., \& Raemer, D. (2007). Debriefing with good judgement: Combining rigorous feedback with genuine inquiry. Anesthesiology Clinics, 25(2), 361-376.

Spur, J., Gatward, J., Joshi, N., \& Carley, S. (2016). Top 10 (+1) tips to get started with in-situ simulation. Emergency Medicine Journal, 33, 514-516. doi:10.1136/emermed-2015-204845

Thomson, N., Tan, M., Hellings, S., Frys, L. (2016). Integrating regular multidisciplinary 'insitu' simulation into the education programme of a critical care unit. How we do it. Journal of the Intensive Care Society (pp. 73-74). Conference: Intensive Care Society State-of-the-Art

Weller, J., \& Civil, I. (2017). Teamwork in healthcare simulation. In Healthcare Simulation Education, Theory and Practice (pp. I27134). Wiley Online. Retrieved December 15, 2018.

Yajamanyam, P., Sohi, D., King, S., Wikey, O., Sinclair, H. (2012). Latent error detection during in-situ simulation training in a district general hospital. Archives of Childhood Disease. 97, pp. Al77-AI78. Glasgow, United Kingdom: Conference: Annual Conference of the Royal College of Paediatrics and Child Health. 